\title{
Education in the genetics of hearing loss: A survey of early hearing detection and intervention programs
}

Sarah K. Burton, $M S^{1}$, Susan H. Blanton, PhD ${ }^{2,3}$, Brandt Culpepper, $P h D^{4}$, Karl R. White, PhD ${ }^{5}$, Arti Pandya, $M D^{2}$, Walter E. Nance, $\mathrm{MD}, \mathrm{PhD}^{2}$, and Kathleen S. Arnos, $\mathrm{Ph} \mathrm{D}^{1}$

\begin{abstract}
Purpose: Permanent hearing loss at birth or in early childhood is common and has many genetic and environmental causes. Advances in the identification and characterization of genetic forms, combined with the early identification of children through the implementation of state-based Early Hearing Detection and Intervention programs suggests the need for education about the causes of hearing loss among professionals who work in these programs. Methods: An online survey was directed to state program coordinators of Early Hearing Detection and Intervention programs to identify gaps in knowledge about the genetic causes of hearing loss and to assess interest in continuing education on this topic. Results: The study identified clear gaps in respondents' knowledge about genetic causes of hearing loss. Twenty percent of respondents indicated that they had received no training in genetics. When asked to rate their knowledge about the genetics of hearing loss, most rated their knowledge as "not adequate." Respondents expressed interest in genetics training through several modalities, including a distance learning format. Conclusion: This study provides documentation of the need for education of health care professionals involved in the early identification of hearing loss. Suggestions for suitable educational formats based on respondent needs and interests are provided. Genet Med 2006:8(8):510-517.
\end{abstract}

Key Words: genetics education, hearing loss, early hearing detection and intervention

Hearing loss (HL) is an etiologically heterogeneous trait with many recognized genetic and environmental causes. ${ }^{1,2}$ The incidence of profound deafness at birth is about 0.8 per 1,000 live births and another 1-2 infants/1,000 births have a lesser but clinically significant loss of $30 \mathrm{~dB}$ HL or greater in at least one ear. Despite the establishment of newborn hearing screening programs throughout the United States and around the world, comparable estimates of the incidence and specific causes of deafness remain elusive because of major differences in screening and testing protocols, equipment, screening and diagnostic criteria, variable follow-up for audiologic confirmation, the recognition that some forms of pre-lingual deafness are not expressed at birth, and the lack of an etiologic focus in most screening programs. ${ }^{3}$

Approximately $60 \%$ of hearing loss present at birth or beginning within the first few months of life results from alterations in one or more of an estimated 400 genes involved in the

\footnotetext{
From the ${ }^{I}$ Genetics Program, Department of Biology, Gallaudet University, Washington, DC; ${ }^{2}$ Department of Human Genetics, Virginia Commonwealth University, Richmond, VA; ${ }^{3}$ Department of Pediatrics, University of Virginia, Charlottesville, VA; ${ }^{4}$ Audiology Services, Northside Hospital, Atlanta, GA; and ${ }^{5}$ National Center for Hearing Assessment and Management, Utah State University, Logan, UT.

Kathleen S. Arnos, PhD, Director, Genetics Program, Department of Biology, 800 Florida Avenue, NE, Washington, DC 20002

Submitted for publication April 14, 2006.
}

Accepted for publication May 25, 2006.

DOI: 10.1097/01.gim.0000232462.55966.92 determination of the structure and function of the organ of hearing. ${ }^{4}$ More than 100 loci for non-syndromic deafness have now been mapped and at least 40 of the genes at these loci have been cloned. ${ }^{5}$ However, despite the large number of genes that are capable of causing deafness, mutations involving a single gene at the DFNB1 locus, GJB2, which encodes the connexin 26 protein, account for approximately $30-40 \%$ of all profound, congenital or early-onset hereditary deafness in the United States. ${ }^{6,7}$ A $309 \mathrm{~kb}$ deletion of GJB6 has been shown to cause deafness when present in the homozygous state or in trans with GJB2 mutations. ${ }^{8,9}$ GJB6 is a functionally related gene telomeric to GJB2 at the DFNB1 locus. GJB6 encodes the connexin 30 protein. Mutation screening for GJB2 and GJB6 is now widely available for clinical testing. Similarly, diagnostic DNA testing for some less common forms of syndromic and non-syndromic deafness is already available and the number of forms of hereditary deafness for which tests are available is likely to increase in the future. Interestingly, based on a recent study in the United Kingdom, it has been suggested that screening for genes other than GJB2 in Caucasian children produces a very low yield and is not cost-effective. ${ }^{10}$

Early diagnosis and intervention (before six months of age) can have a dramatic effect on improving the communication skills and the educational achievement of children with hearing loss. ${ }^{11,12}$ At present, all states and territories in the US have either passed legislation for universal newborn hearing screen- 
ing or are voluntarily screening, resulting in approximately $93 \%$ of all newborns having their hearing screened before discharge from the newborn nursery. ${ }^{13}$ Because of these Early Hearing Detection and Intervention (EHDI) programs, the average age at which hearing loss is identified has progressively declined, and the early enrollment of infants with hearing loss and their families into early intervention programs will maximize the benefits they experience.

The Joint Committee on Infant Hearing recommends that in all cases where the etiology of hearing loss is uncertain, "families should be offered the option of genetic evaluation." 14 Partly in response to this recommendation, in 2002, the American College of Medical Genetics convened a group of clinicians, researchers, and health policy experts from the fields of genetics, audiology and otolaryngology to develop guidelines for the genetic evaluation of children with hearing loss. ${ }^{15}$ The resulting recommendations emphasize the importance of multidisciplinary cooperative working relationships among professionals to ensure the appropriate genetics evaluation of children with hearing loss. EHDI programs provide a logical venue for the initial provision of information about the importance of genetics evaluation and testing. ${ }^{16}$ While many issues remain to be resolved regarding the appropriate timing for genetic testing, the types of genetic testing that should be offered, and the most appropriate mechanism for delivering information and counseling to parents, ${ }^{17,18}$ it seems clear that the genetic evaluation and appropriate testing of all infants with confirmed hearing loss is becoming the standard of care in this country. As the clinical applications of genetic testing become more widespread, professionals affiliated with EHDI programs need to have a basic understanding of the process and value of genetic evaluation, the benefits and limitations of molecular testing, and the genetic resources that are available to deaf infants and their families.

The present study was designed to evaluate the degree to which EHDI state coordinators and other professionals affiliated with those programs were knowledgeable about the genetic and environmental causes of hearing loss and to determine the need for and interest of this group in educational programs on this topic. These data should facilitate the development of educational programs to meet this need, including the specific content and most appropriate educational strategies.

\section{MATERIALS AND METHODS}

A web-based survey with 14 items was designed by the project team (see Appendix). The first few items collected information on the respondents' current position, state affiliation and professional background (audiologist, nurse, physician, etc.). Information was also collected about prior training in genetics, and each respondent was asked to rate their knowledge of both general genetics and the genetics of hearing loss. Respondents were then asked how common it was for all EHDI professionals in their state to discuss genetics with newly diag- nosed families, to provide referral for genetic evaluation, counseling or testing, or to provide counseling about or a referral for genetic tests. The second section of the survey assessed information regarding preferences for further education in genetics including topics of interest, potential educational formats, factors that might restrict the ability to participate and the benefit of specific educational materials for consumers.

The survey questions were imported to the Perseus online survey tool. Perseus is specialized for the development, deployment, and analysis of surveys and supports the collection of responses via the web. A cover letter from KSA and KRW containing a link to the online survey was sent by electronic mail to all EHDI state coordinators in November 2004, and the coordinators were urged to forward the survey to other relevant EHDI professionals in their states. The survey responses were collected through Perseus and then imported into a Microsoft Access database and analyzed with the Statistical Analysis System (SAS) software package.

\section{RESULTS}

\section{Respondent characteristics}

Completed responses were received from 53 individuals from 36 states and three territories. Thirty-two (60\%) responses were from EHDI state coordinators, $14(26 \%)$ from other EHDI staff members and 7 (13\%) of the respondents were genetic counselors or clinical geneticists. The geneticists were largely affiliated with state metabolic newborn screening programs, and were not specialists in the EHDI programs. As shown in Table 1, while the respondents had a wide range of professional backgrounds, $26(49 \%)$ were audiologists or nurses. As shown in Table 2, five (16\%) of the state coordinators and four $(29 \%)$ of other staff had no previous training in genetics. During the last six months, the EHDI coordinators and other EHDI professionals reported that they had learned

Table 1

Professional background of 53 survey respondents

\begin{tabular}{lcc}
\hline Professional background & N & Percent of total \\
\hline Audiologist & 16 & 30.2 \\
Nurse & 10 & 18.9 \\
Clinical geneticist or genetic & 7 & 13.2 \\
$\quad$ counselor & 3 & 5.6 \\
Physician (non-geneticist) & 3 & 5.6 \\
Public health professional & & \\
$\quad$ (non-physician) & 2 & 3.8 \\
Speech/language pathologist & 2 & 3.8 \\
Masters in education & 2 & 3.8 \\
Social worker & 1 & 1.9 \\
Parent of a deaf child & 7 & 13.2 \\
Other & 53 & 100.0 \\
Total & & \\
\hline
\end{tabular}




\section{Burton et al.}

Table 2

Percentage of respondents reporting various levels of training by position ${ }^{\mathbf{a}}$

Position

\begin{tabular}{lccc}
\cline { 2 - 4 } & $\begin{array}{c}\text { EHDI } \\
\text { Coordinators } \\
(\mathrm{N}=32)\end{array}$ & $\begin{array}{c}\text { Geneticists } \\
(\mathrm{N}=7)\end{array}$ & $\begin{array}{c}\text { Other } \\
(\mathrm{N}=14)\end{array}$ \\
\hline $\begin{array}{c}\text { Level of training } \\
\text { education }\end{array}$ & $31.3 \%$ & $28.6 \%$ & $21.4 \%$ \\
$\begin{array}{l}\text { On the job training } \\
\begin{array}{c}\text { Periodic genetics content } \\
\text { in courses }\end{array}\end{array}$ & $31.3 \%$ & $28.6 \%$ & $35.7 \%$ \\
$\begin{array}{l}\text { One or more semester } \\
\text { courses in genetics }\end{array}$ & $40.6 \%$ & 0.0 & $35.7 \%$ \\
$\begin{array}{c}\text { Bachelors/graduate degree } \\
\text { in biology or genetics }\end{array}$ & $6.3 \%$ & 0.0 & $7.1 \%$ \\
$\begin{array}{l}\text { No training } \\
\text { and }\end{array}$ & $18.8 \%$ & $85.7 \%$ & 0.0 \\
\hline
\end{tabular}

${ }^{a}$ Individuals were allowed to report more than one type of training. Sixteen individuals $(30 \%)$ reported 2 or more training types.

about genetic advances and other genetic issues from professional publications and journal articles $(84 \%$ and $50 \%$, respectively), books and newsletters ( $84 \%$ and $50 \%$, respectively), newspapers and lay publications ( $60 \%$ and $43 \%$, respectively) and in-service or continuing education programs $(44 \%$ and $64 \%$, respectively).

Seventeen $(53 \%)$ of the state coordinators and $5(36 \%)$ of the other EHDI staff indicated that their knowledge of general genetics was not adequate (data not shown). As shown in Figure 1, when asked about their knowledge about genetic hearing loss specifically, $14(44 \%)$ of the state coordinators and 5 (36\%) of the other staff indicated their knowledge was inadequate. None of the geneticists rated their knowledge about genetic hearing loss as excellent.

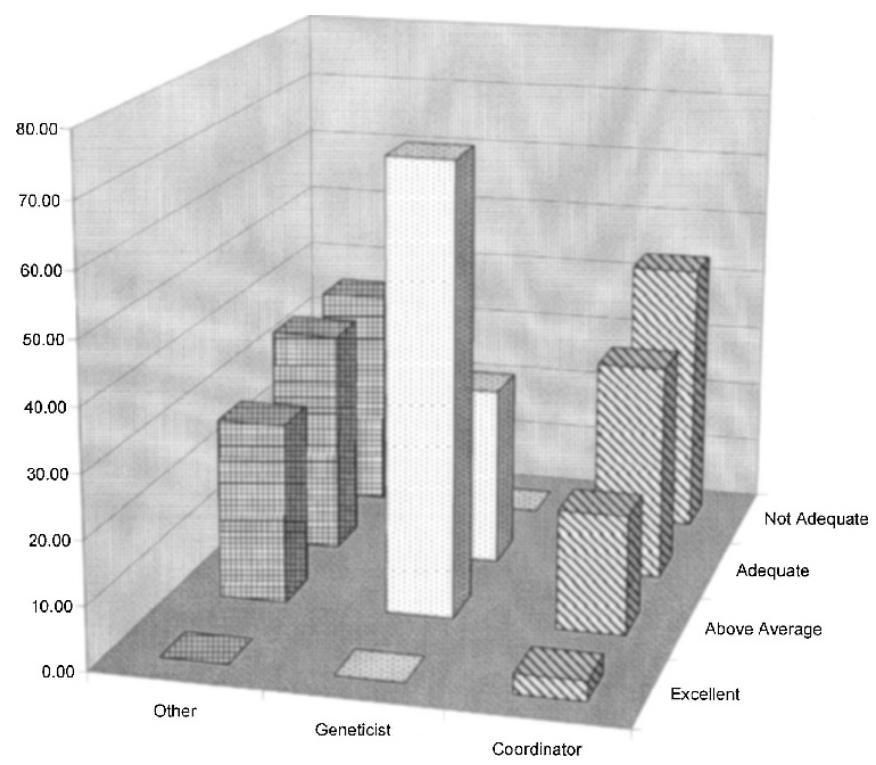

Fig. 1. Relationship between type of professional and self-reported rating of knowledge about the genetics of hearing loss.
Table 3

Percentage of responses to the question "Based on your experience, how common is it that EHDI professionals in your state do the following with newly-diagnosed families?"

\begin{tabular}{lccc}
\hline & Always & Sometimes & $\begin{array}{c}\text { Almost } \\
\text { never to never }\end{array}$ \\
\hline $\begin{array}{l}\text { Discuss possibility that hearing } \\
\text { loss can be genetic }\end{array}$ & $13.7 \%$ & $72.6 \%$ & $13.5 \%$ \\
$\begin{array}{l}\text { Make referrals for genetic } \\
\text { counseling }\end{array}$ & $8.0 \%$ & $62.0 \%$ & $30.0 \%$ \\
$\begin{array}{l}\text { Make referrals for genetic } \\
\text { testing }\end{array}$ & $4.1 \%$ & $59.2 \%$ & $35.7 \%$ \\
$\begin{array}{l}\text { Provide counseling about } \\
\text { genetic conditions }\end{array}$ & $8.5 \%$ & $46.8 \%$ & $44.7 \%$ \\
\begin{tabular}{l} 
Order genetic tests \\
\hline
\end{tabular} & 0.0 & $46.9 \%$ & $53.1 \%$ \\
\hline
\end{tabular}

\section{Genetic services in EHDI programs}

Table 3 summarizes the responses to the question, "Based on your experience, how common is it that EHDI professionals in your state do the following with newly-diagnosed families?" First, respondents were asked about the frequency with which EHDI professionals in their state "discuss the possibility that the hearing loss can have a genetic cause." Fourteen percent of respondents said it was always discussed, $73 \%$ indicated that it was sometimes discussed and $14 \%$ indicated that it was almost never or never discussed. Referrals for genetic counseling were made less frequently, with $8 \%$ of respondents indicating that referrals were always made, $62 \%$ indicating they were sometimes made and 30\% indicating that referrals for genetic counseling were almost never or never made. Comparable percentages were obtained concerning referrals for genetic testing.

\section{Educational options}

The final section of the survey addressed personal preferences for education in genetics. A list of topics was provided and respondents were asked to rate their interest in each topic. While only $45 \%$ of the group was "very interested" in a review of basic genetics and $26 \%$ in a review of advanced genetics, $87 \%$ were "very interested" in further education about the genetics of hearing loss and $66 \%$ about genetic counseling for hearing loss. Table 4 shows data for additional items specifically related to the genetics of hearing loss. Lesser interest was indicated for only two survey items with fewer than half of respondents indicating that they were "very interested" in the molecular/biochemical basis of hearing loss (43\%) and strategies for making referrals (46\%).

Respondents were also asked to indicate their interest in a variety of educational formats. Choices included review articles in professional journals, seminars at professional conferences, interactive $\mathrm{CD}-\mathrm{ROM}$, web-based instructional programs with continuing education credit, and printed material in the form of brochures. There was no clear preference, with most respondents endorsing a wide variety of educational formats. However, travel time, fees, and other expenses were identified as major factors that would limit their ability to 
Table 4

Percentage of responses to the genetics education query "Related to hearing loss, how interested would you be in learning about the following topics?"

\begin{tabular}{lccc}
\hline Topics & $\begin{array}{c}\text { Very } \\
\text { interested }\end{array}$ & $\begin{array}{c}\text { Somewhat } \\
\text { interested }\end{array}$ & $\begin{array}{c}\text { Slight to } \\
\text { no interest }\end{array}$ \\
\hline Epidemiology & $59.6 \%$ & $26.9 \%$ & $13.5 \%$ \\
Modes of inheritance & $58.8 \%$ & $29.4 \%$ & $11.8 \%$ \\
$\begin{array}{l}\text { Non-syndromic forms of hearing loss } \\
\text { Syndrome with hearing loss as } \\
\text { major finding }\end{array}$ & $65.4 \%$ & $26.9 \%$ & $7.7 \%$ \\
$\begin{array}{l}\text { Specific genes associated with } \\
\text { hearing loss }\end{array}$ & $67.3 \%$ & $38.8 \%$ & $1.9 \%$ \\
$\begin{array}{l}\text { Genetic newborn screening for } \\
\text { hearing loss }\end{array}$ & $66.7 \%$ & $23.5 \%$ & $9.8 \%$ \\
$\begin{array}{l}\text { Molecular/biochemical basis of } \\
\text { hearing loss }\end{array}$ & $73.1 \%$ & $25.0 \%$ & $1.9 \%$ \\
$\begin{array}{l}\text { Current research topics in genetics } \\
\text { of hearing loss }\end{array}$ & $63.1 \%$ & $39.2 \%$ & $17.7 \%$ \\
$\begin{array}{l}\text { Deaf culture and perspectives on } \\
\text { genetic tests }\end{array}$ & $57.4 \%$ & $21.1 \%$ & $13.5 \%$ \\
$\begin{array}{l}\text { Strategies for making referrals to } \\
\text { genetics }\end{array}$ & $46.2 \%$ & $28.8 \%$ & $24.0 \%$ \\
$\begin{array}{l}\text { Disseminating information on } \\
\text { genetics to parents }\end{array}$ & $61.5 \%$ & $26.9 \%$ & $11.5 \%$ \\
$\begin{array}{l}\text { Disseminating information to } \\
\text { hospitals doing NBHS }\end{array}$ & $55.8 \%$ & $30.8 \%$ & $13.4 \%$ \\
\hline
\end{tabular}

participate in whatever educational activities were available. Conversely, access to a computer and a slow internet connection were seen as "not prohibitive" by $98 \%$ and $83 \%$ of respondents, respectively. Finally, a query was included regarding how beneficial certain formats for parent or family education in genetics would be. Respondents indicated that a wide variety of formats were potentially beneficial, especially brochures on specific diagnoses ( $70 \%$ of respondents indicated this would be "very beneficial"), a brochure providing an overview of genetic testing and counseling (62\% "very beneficial") and an interactive website for parent/patient education (51\% "very beneficial"). Write-in comments regarding parent and family educational formats indicated that parent-friendly and Spanish language materials were viewed as very important. A few respondents also expressed interest in short, accurate paragraphs of information regarding genetics and hearing loss that could be incorporated into existing state-based EDHI materials such as brochures and web pages.

\section{DISCUSSION}

Education in human genetics has become increasingly important for allied health care professionals. The argument can be made that the need for genetics education for those health care professionals who work in the identification and habilitation of children with congenital and earlyonset hearing loss currently surpasses that of other groups because of the recent introduction of universal newborn hearing screening programs, the high frequency of children with permanent hearing loss in comparison to other genetic diseases for which screening is performed, and the major role that genetics plays in the etiology of congenital and early-onset hearing loss. Unlike other conditions such as metabolic disorders for which the clinical geneticist often has a primary role in the identification and subsequent care of affected infants, children with hearing loss are identified and given ongoing care primarily by audiologists and otologists. Robin et al. ${ }^{19}$ contend that pediatric otolaryngologists should provide pre-test and post-test genetic counseling themselves, while limiting referrals to genetics to cases with complex testing results or difficult counseling issues. However, results of their survey of a small group of pediatric otolaryngologists found that while this group had a good knowledge of genetics, they did not have adequate knowledge to provide accurate recurrence risks, documenting the need for further education in the genetics of hearing loss for this group.

The number of tests available to diagnose specific genetic forms of hearing loss will likely increase rapidly in the near future and technological advances will enable testing to become more widespread and cost effective. Another important issue is the possible future use of molecular newborn screening for common forms of congenital and late-onset hearing loss. While molecular testing will never be a replacement for physiologic screening for hearing loss, it could be an effective adjunct to physiologic testing to determine the cause of the hearing loss in cases with a congenital onset as well as infants at risk for late-onset pre-lingual hearing loss. ${ }^{17,18} \mathrm{EHDI}$ professionals are the first to come into contact with parents of newly-diagnosed children with hearing loss. A proactive approach to professional education would require that the foundations of knowledge regarding the genetics of hearing loss among this group be firmly in place before the implementation of molecular newborn screening to allow for the efficacious introduction of such testing.

The current study provides survey data regarding a very specific group of professionals involved in the identification of children with hearing loss and offers evidence of the need for and interest in education in the genetics of hearing loss by this group. The majority of respondents to this survey were EHDI state coordinators who are responsible for establishing and administering the day-to-day operations of newborn hearing screening in what can be hundreds of different hospitals and birthing centers within their states. Analysis of survey responses indicates that many of these professionals recognize that their knowledge of the genetics of hearing loss is not adequate. Even among the small group of geneticists who responded, none rated their knowledge of the genetics of hearing loss as "excellent." The most common sources of background knowledge in genetics were reported to be "on-the-job training" or "periodic school courses" which may have taken place many years ago. A small group of respondents reported that they had completed at least one in-service or continuing education program in genetics, but very few of the respondents 
who were non-geneticists ( $89 \%$ of the sample) indicated that they had ever taken coursework in genetics during their education or professional training.

A startling percentage of respondents reported that, in their states, EHDI professionals almost never or never made referrals for genetic counseling or testing. This may indicate that EHDI professionals are not comfortable making such referrals or feel that there are insufficient geneticists locally to whom they can refer. It is also possible that referrals in these states are made only by physicians who are not directly affiliated with the EDHI programs. Arguing against this however, a recent study found that only $8 \%$ of 1,968 physicians who responded to a survey about EHDI programs indicated that they would refer a child with a bilateral severe/profound permanent hearing loss to a geneticist. ${ }^{20}$ These results certainly indicate the need for primary care physicians, including pediatricians and otolaryngologists to be educated about the appropriateness of genetic evaluation, and may also indicate that the emphasis at the earliest stages of diagnosis of hearing loss is on confirming the diagnosis rather than investigating the cause of hearing loss. The fact that only a very small percentage of respondents to the EHDI survey (13\%) indicated that genetics was "always" discussed as a possible cause for hearing loss with newly-diagnosed families seems to confirm this lack of an etiologic focus in most screening programs.

The results of this survey clearly document the need for continuing education programs in the genetics of hearing loss for EHDI professionals. Based on survey responses, a web-based format would work well since virtually all respondents indicated that access to a computer with a fast internet connection would not be a major obstacle to participation in continuing education. Web-based courses would also address respondents' concerns about time for travel and time away from work to participate in education programs. In a similar study we have documented deficiencies in the graduate-level training of audiologists in the genetics of hearing loss. ${ }^{21}$ The results of this study were used to develop a comprehensive educational program de-signed to assist faculty from graduate-level training programs in audiology to incorporate information about genetics and hearing loss into their curricula. This program can serve as a successful model for the education of other professionals about the genetic and environmental causes of hearing loss.

Educational programs that are focused on specific topics in genetics can empower health care professionals with the basic knowledge necessary to initiate the referral process and ensure that appropriate follow-up is obtained. There is also a need for human geneticists to develop strong collaborative relationships with EHDI professionals so that the transfer of knowledge regarding this rapidly changing field can occur on a continuing basis. This could be accomplished through personal interactions at the program level, ongoing continuing education, increased efforts by geneticists to publish review articles in the professional literature of other medical specialties and appropriate recognition to those who do so, and participation of geneticists in state or national meetings of EHDI professionals.

\section{ACKNOWLEDGMENTS}

This study was supported by grant number 5 R25 DC005543 to KSA from the National Institute on Deafness and Other Communication Disorders (NIDCD) and the National Human Genome Research Institute, National Institutes of Health (NIH). SKB, SHB, AP, WEN and KSA are also supported by NIDCD/NIH grants 1 R01 DC006707 to KSA and 1 R01 DC005831 to AP. The authors wish to thank all of the responding state EHDI programs and program coordinators for their assistance with this study.

\section{References}

1. Tekin M, Arnos KS, Pandya A. Advances in hereditary deafness. Lancet 2001;358: 1082-1090.

2. Nance WE. The genetics of deafness. Ment Retard Dev Disabil Res Rev 2003;9:109-119.

3. Morton C, Nance WE. Newborn hearing screening - a silent revolution. N Engl J Med 2006;354:2151-2164.

4. Marazita ML, Ploughman LM, Rawlings B, Remington E, et al. Genetic epidemiological studies of early-onset deafness in the U.S. school-age population. Am J Med Genet 1993;46:486-491.

5. VanCamp G, Smith RJH. Hereditary hearing loss homepage. Available at: http:// webhost.ua.ac.be/hhh/. Accessed on: January 20, 2006.

6. Cohn ES, Kelley PM, Fowler TW, Gorga MP, et al. Clinical studies of families with hearing loss attributable to mutations in the connexin 26 gene (GJB2/DFNB1). Pediatrics 1999;103:546-550.

7. Kenneson A, Van Naarden BK, Boyle C. GJB2 (connexin 26) variants and nonsyndromic sensorineural hearing loss: a HuGE review. Genet Med 2002;4:258-274.

8. del Castillo I, Villamar M, Moreno-Pelayo MA, Del Castillo FJ, et al. A deletion involving the connexin 30 gene in nonsyndromic hearing impairment. N Engl J Med 2002;346:243-249.

9. Del Castillo FJ, Rodriguez-Ballesteros M, Alvarez A, Hutchin T, et al. A novel deletion involving the connexin-30 gene, $\operatorname{del}(\mathrm{GJB} 6-\mathrm{d} 13 \mathrm{~s} 1854)$, found in trans with mutations in the GJB2 gene (connexin-26) in subjects with DFNB1 non-syndromic hearing impairment. J Med Genet 2005;42:588-594.

10. Hutchin T, Coy NN, Conlon H, Telford E, et al. Assessment of the genetic causes of recessive childhood non-syndromic deafness in the UK - implications for genetic testing. Clin Genet 2005;68:506-512.

11. Yoshinaga-Itano C. Levels of evidence: universal newborn hearing screening (UNHS) and early hearing detection and intervention systems (EHDI). J Commun Disord 2004;37:451-465.

12. Downs MP, Yoshinaga-Itano C. The efficacy of early identification and intervention for children with hearing impairment. Pediatr Clin North Am 1999;46:79-87.

13. National Center for Hearing Assessment and Management homepage. Available at: http://www.infanthearing.org/ Accessed on: March 20, 2006.

14. Joint Committee on Infant Hearing, American Academy of Audiology, American Academy of Pediatrics, American Speech-Language-Hearing Association, and Directors of Speech and Hearing Programs in State Health and Welfare Agencies. Year 2000 position statement: principles and guidelines for early hearing detection and intervention programs. Pediatrics 2000;106:798-817.

15. Genetic Evaluation of Congenital Hearing Loss Expert Panel. Genetics Evaluation Guidelines for the Etiologic Diagnosis of Congenital Hearing Loss. ACMG statement. Genet Med 2002;4:162-171.

16. White KR. Early hearing detection and intervention programs: opportunities for genetic services. Am J Med Genet A 2004;130:29-36.

17. Schimmenti LA, Martinez A, Fox M, Crandall B, et al. Genetic testing as part of the early hearing detection and intervention (EHDI) process. Genet Med 2004; 6:521-525.

18. Robin NH. Genetic testing for deafness is here, but how do we do it? Genet Med 2004;6:463-464.

19. Robin NH, Dietz C, Arnold JE, Smith RJ. Pediatric otolaryngologists' knowledge and understanding of genetic testing for deafness. Arch Otolaryngol Head Neck Surg 2001;127:937-940.

20. Moeller MP, White K. Attitudes, Knowledge and Practices of Physicians related to Early Hearing Detection and Intervention. Invited paper presented at $2006 \mathrm{National}$ Early Hearing Detection and Intervention Meeting. Washington DC, February 1, 2006.

21. Arnos KS, de la Rocca MG, Karchmer MA, Culpepper B, et al. Genetics content in the graduate audiology curriculum: a survey of academic programs. Am J Audiol 2004;13:126-134. 


\section{Appendix}

EHDI coordinators' knowledge of and interest in the genetics of hearing loss

Section 1: Information About You

1. What is your current position?

2. What state or territory do you represent?

3. Your background:
a. Audiology
b. Nursing
c. MD (please specify your specialty)
d. MPH (please specify your emphasis)
e. Other (please specify)

4. How much training have you received in genetics?

a. I have completed continuing education on genetics.

b. I have on the job training in genetics.

c. My exposure was mainly periodic genetics content in school courses.

d. I completed one or more semester courses specifically in genetics.

e. I have a bachelors or graduate degree in biology / genetics.

$\mathrm{f}$. I have no training in genetics.

5. Within the last six months, from which of the following sources have you learned about genetic advances and genetic issues? (Circle all that apply)
a. Newspapers/magazines
f. In-services or continuing education
b. Television/radio
g. Genetic professionals
c. Internet/World Wide Web
h. Genetic support groups
d. Professional newsletters/journals/books
i. Clients with genetic conditions
e. Professional conferences
j. Other (please specify)

6. Have you had the opportunity to attend seminars/workshops in human genetics? Yes No

If yes, approximately how many training sessions on Human Genetics have you attended?
a. $1-2$
b. $3-5$
c. More than 5

7. How would you rate your general knowledge of genetics?
a. Excellent
b. Above average
c. Adequate
d. Not adequate

8. How would you rate your knowledge of the genetics of hearing loss, specifically?
a. Excellent
b. Above average
c. Adequate
d. Not adequate

9. Based on your experience, how common is it that EHDI professionals in your state do the following with newly-diagnosed families?

a. Discuss the possibility that the hearing loss have a genetic cause

b. Make referrals for genetic counseling

Always Sometimes Almost Never Never

4

4
2

2 
c. Make referrals for genetic testing

3

d. Provide counseling about genetic conditions

e. Order genetic tests

ection 2: Your preferences regarding further genetics education

10. How interested would you be in learning about the following topics:
a. Basic genetics review
b. Advanced genetic concepts
c. Genetics of hearing loss
d. Family history and pedigree analysis
e. Interpreting genetic test results
f. Genetic discrimination/privacy issues
g. Utilizing the scientific literature on genetics
h. Genetic counseling for hearing loss
i. Genetic internet resources
j. Genetic support groups
k. Emerging issues in genetics (Human Genome Project, future directions, ethical issues)

Very
Interested
4
4
4
4
4
4
4
4
4
4
4

Not Interested

1

1

1

1

1

1

1

1

1

1

1

11. Related to hearing loss, how interested would you be in learning about the following topics:
a. Epidemiology
b. Modes of inheritance
c. Non-syndromic forms of hearing loss
d. Syndromes with hearing loss as a major finding
e. Specific genes associated with hearing loss
f. Genetic newborn screening for hearing loss
g. Molecular/biochemical basis of hearing loss
h. Current research topics in genetics of hearing loss
i. Deaf culture and perspectives on genetic tests
j. Strategies for making referrals to genetics

k. Strategies, timing and appropriateness for disseminating information on genetics to parents

1. Strategies for disseminating information on genetics to hospitals doing NBHS in my state

12. How interested would you be in using the following formats to receive educational material on genetics or new advances in hearing loss?

$\begin{array}{llll}4 & 3 & 2 & 1 \\ 4 & 3 & 2 & 1 \\ 4 & 3 & 2 & 1 \\ 4 & 3 & 2 & 1 \\ 4 & 3 & 2 & 1 \\ 4 & 3 & 2 & 1 \\ 4 & 3 & 2 & 1 \\ 4 & 3 & 2 & 1 \\ 4 & 3 & 2 & 1 \\ 4 & 3 & 2 & 1 \\ 4 & 3 & 2 & 1 \\ 4 & 3 & 2 & 1\end{array}$

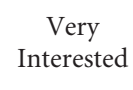
a. Review article in audiology/otology/medical journals
b. Seminar at professional conference
c. Interactive CD-Rom (education / reference)
d. Web-based instructional program with CEUs
e. Brochure on specific diagnoses/categories of hearing loss
f. Brochure reviewing available genetic tests for hearing loss
g. Other (please specify)

Not Interested

4
4
4
4
4
4
4


Appendix

Continued

13. What things would prohibit or restrict your ability to participate in education or training if it were available?

Very
Interested

Not

Interested
a. Travel to and from a particular location
b. Time away from work
c. Registration and materials fees
d. Limited access to computers
e. Slow internet connection
f. Other (please specify)

4

$\begin{array}{ll}4 & 3 \\ 4 & 3 \\ 4 & 3 \\ 4 & 3 \\ 4 & 3 \\ 4 & 3\end{array}$

1
1
1
1
1

14. How beneficial do you believe the following materials would be for your patients or families with hearing loss?

$$
\begin{gathered}
\text { Very } \\
\text { Interested }
\end{gathered}
$$

Brochures on a specific diagnosis/category of hearing loss

Brochure overview of genetic testing and genetic counseling

Interactive CD-Rom for patient education

\begin{tabular}{llll}
4 & 3 & 2 & 1 \\
4 & 3 & 2 & 1 \\
4 & 3 & 2 & 1 \\
4 & 3 & 2 & 1 \\
4 & 3 & 2 & 1 \\
\hline
\end{tabular}

